\title{
Peptide Amphiphile Nanofibers Template and Catalyze Silica Nanotube Formation
}

\author{
Virany M. Yuwono and Jeffrey D. Hartgerink ${ }^{*}$ \\ Departments of Chemistry and Bioengineering, Rice University, 6100 Main St. MS. 60, Houston, \\ Texas 77005
}

Supporting Information

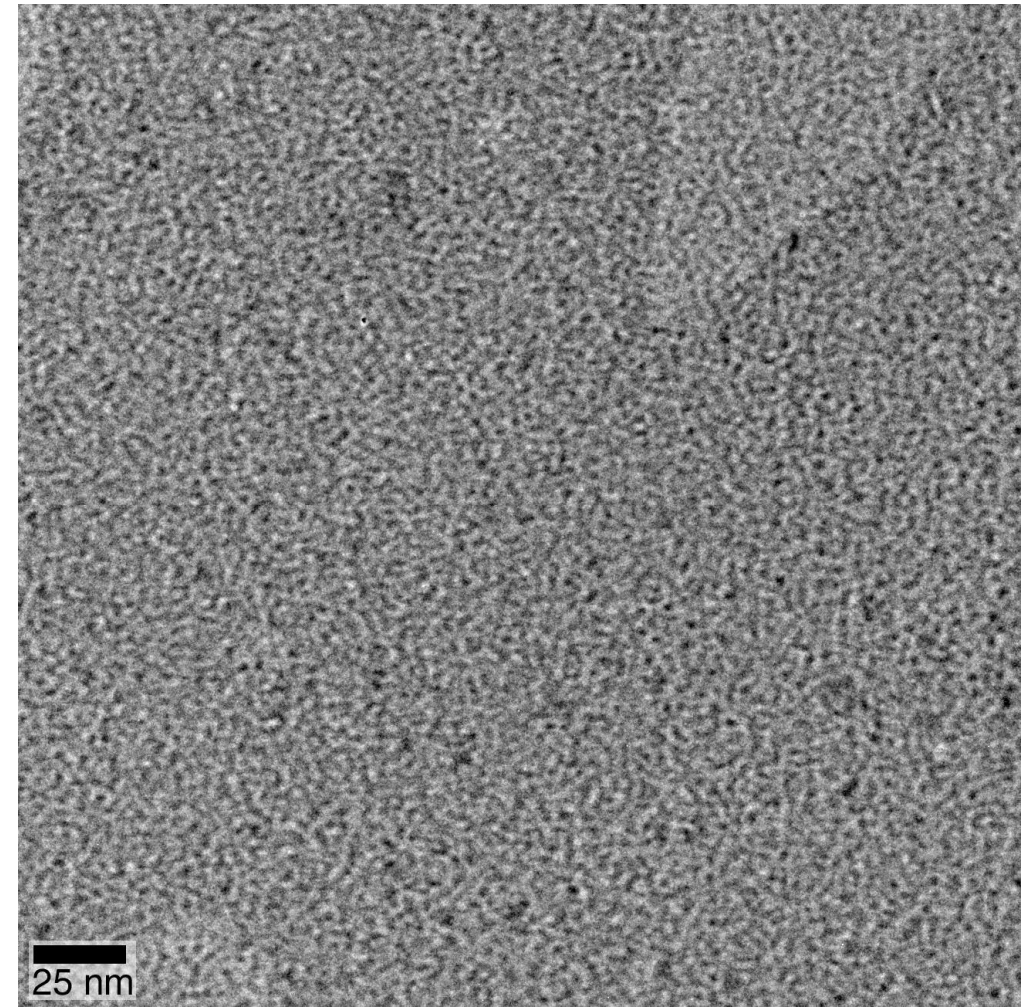

Figure S1. Control experiment at pH 10, no PA, $200 \mu \mathrm{L} \mathrm{H}_{2} \mathrm{O}, 200 \mu \mathrm{L}$ ethanol and $20 \mu \mathrm{mol}$ TEOS. 


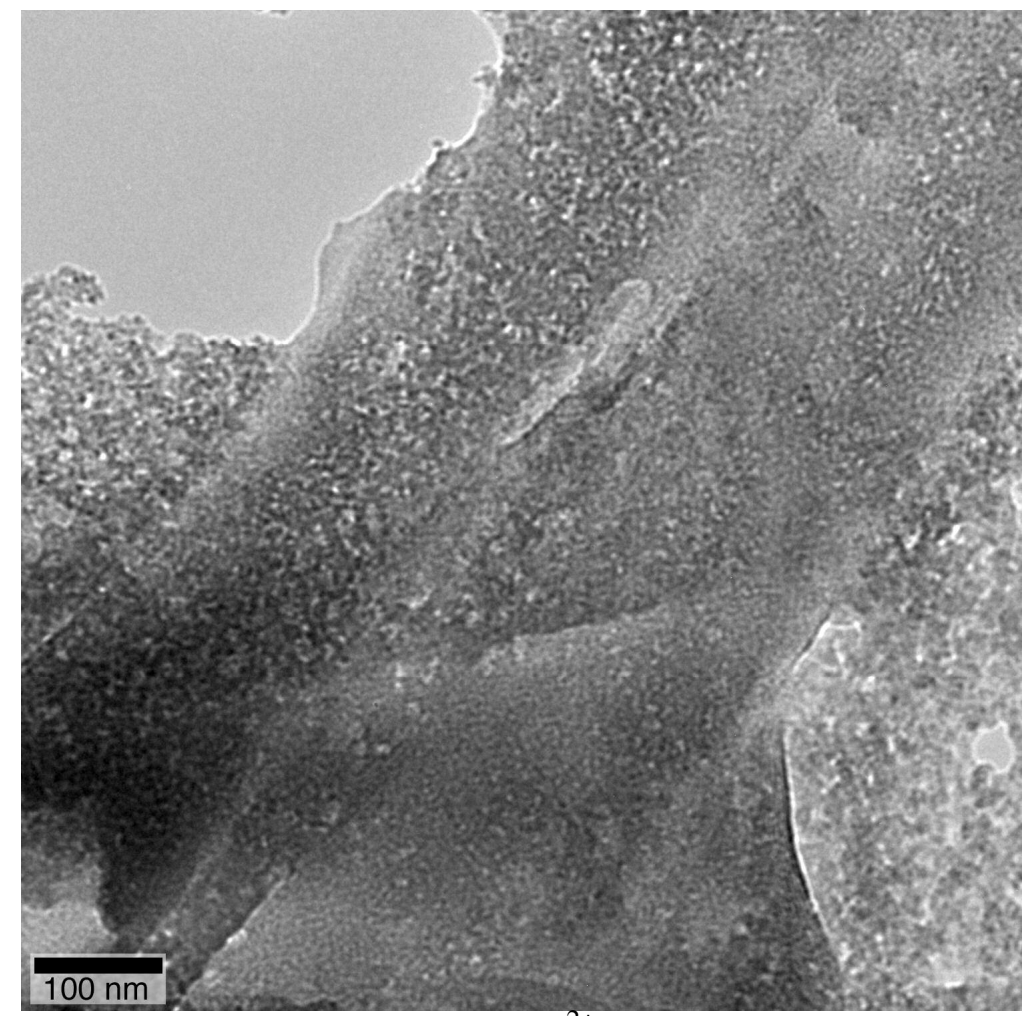

Figure S2. Disassembled PA3 at pH 10 without $\mathrm{Ca}^{2+}$. Other conditions are the same as in sample PA3-3. 


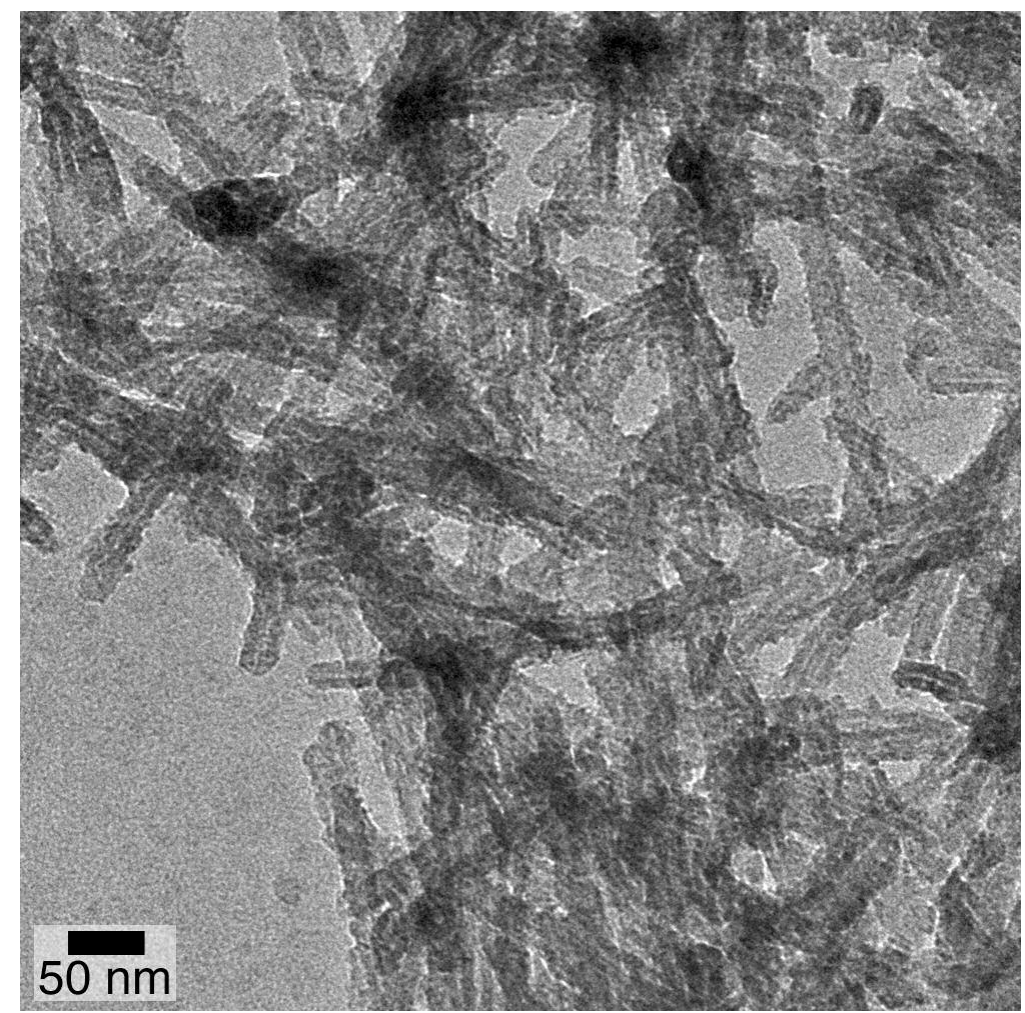

Figure S3. TEM images of silica coated PA4 samples after incubation in TEOS; R = 100, 1 day.

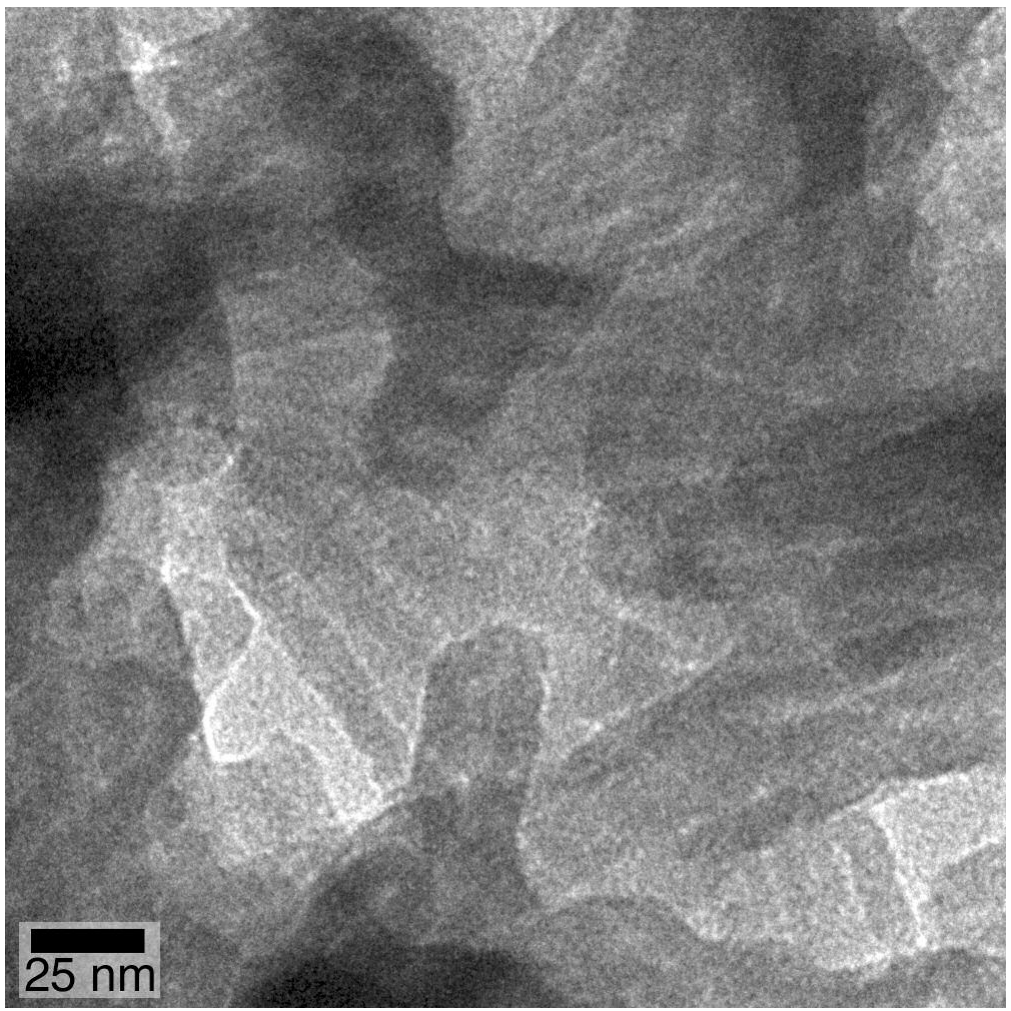

Figure S4. TEM images of silica coated PA5 samples after incubation in TEOS; $[\mathrm{PA}]=1 \mathrm{mM}$, $\mathrm{R}=100,1$ day. 


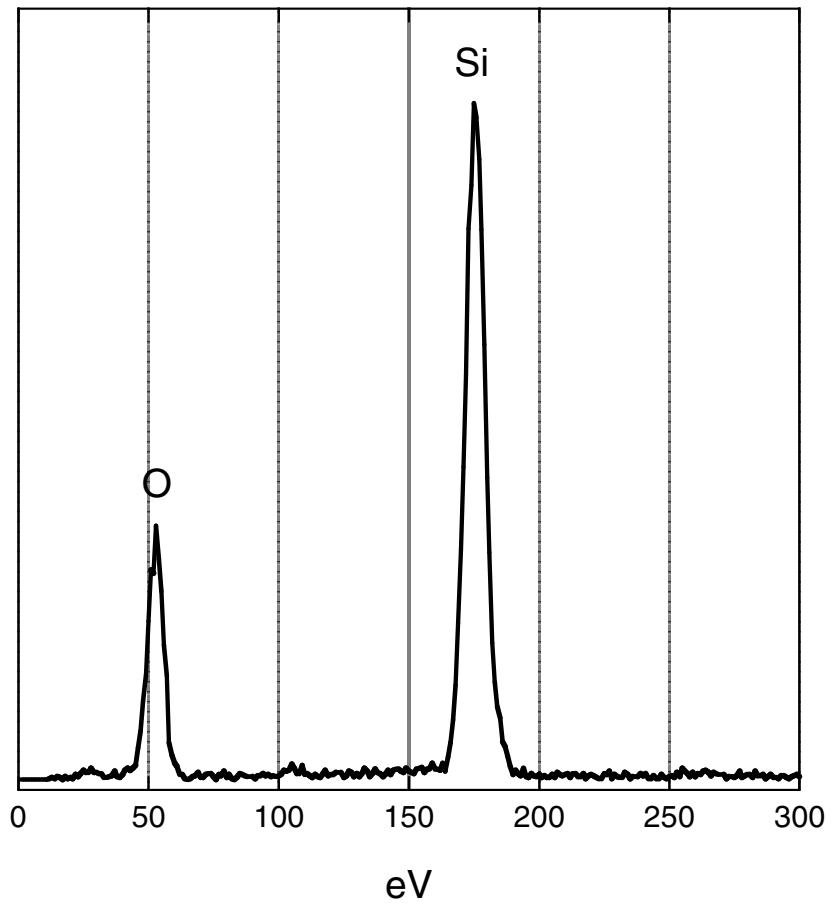

Figure S5. EDX spectrum of silica nanotubes. 